\title{
First Results of ACH Cardioplegic Solution Clinical Application in Newborns and Infants under One Year of Age
}

\author{
L. A. Bockeria, A. A. Boldyrev, O. I. Kulaga, G. A. Blejyants, D. N. Egorov, A. E. Popov, \\ K. V. Mumladze, I. F. Egorova, T. V. Artuhina, N. V. Kalaeva, R. R. Movsesian \\ Bakulev Scientific Center of Cardiovascular Surgery RAMS, Moscow, Russia \\ Email: movses@,bk.ru
}

Received 26 June 2013; revised 28 July 2013; accepted 5 August 2013

Copyright (C) 2013 L. A. Bockeria et al. This is an open access article distributed under the Creative Commons Attribution License, which permits unrestricted use, distribution, and reproduction in any medium, provided the original work is properly cited.

\begin{abstract}
Study objective involved comparison of two cardioplegic solutions: HTK-solution possessing high buffer capacity and a new ACH-solution with aminoacid buffer. Results revealed high cardioprotective efficiency during surgical repair of complex congenital heart disease both in the group that had received $\mathrm{Cu}$ stodiol and in the group that had received $\mathrm{ACH}$-solution. Clinical and morphological parameters demonstrate high level of myocardial protection from intraoperative ischemia for single usage of $\mathrm{ACH}$-solution during cardioplegic ischemia under 60 minutes in duration.
\end{abstract}

Keywords: Cardioplegic Solution Natural Dipeptides; Cardioplegic Ischemia; Immature Myocardium

\section{INTRODUCTION}

Maintaining viability of myocardium following cardiac arrest remains one of the main issues in cardiosurgery since the beginning of the first operations on an open heart. In spite of great progress in the field of congenital heart pathology surgery, intraoperative myocardial damage remains the most common reason for complications and mortality following cardiac surgery. In this regard, the issue of intraoperative myocardial protection retains its relevance continually while cardiosurgery is developing.

Using intracellular cardioplegic solutions possessing high buffer capacity is one of state-of-the-art developments in this field. Among available industrially produced cardioplegic solutions, only HTK-solution possesses increased buffer capacity that is twofold the blood buffer capacity. The main buffer ingredient in this solu- tion is heterocyclic aminoacidhistidine. It is commonly known that protein buffer solutions are preferable for stabilizing of intracellular $\mathrm{pH}$ level and a better recovery of myocardial contractility compared to a bicarbonate buffer that is frequently used in extracellular solutions.

Current studies aim to investigate the possibility of using a combination of several buffer substrates possessing affinity for myocardial protein systems in cardioplegic solutions including the combination of carnosine, $\mathrm{N}$-acetylcarnosine and L-histidine. These components allow increasing the buffer capacity maintaining the physiological $\mathrm{pH}$ level owing to various dissociation degree of histidine-containing dipeptides imidazole groups. Creating cardioplegic solutions based on such buffers is a promising perspective for myocardial metabolism stabilization during cardioplegic ischemia and reperfusion period.

A new intracellular ACH (acetylcarnosine-carnosinehistidine) cardioplegic solution based on histidine-containing peptides has been developed in the Bakulev Scientific Center of Cardiovascular Surgery. After a large set of experiments on rats' isolated hearts over a period of five years and a successful clinical testing on patients with acquired heart valvular disease, we decided to perform a series of operations using this solution on infants under one year of age with complex congenital heart disease.

\section{MATERIALS AND METHODS}

Here we represent data on 40 observations of subjects under one year of age who underwent definitive repair of congenital heart disease under cardiopulmonary bypass conditions. The study was conducted on the base of Department of Intensive Cardiology of Premature Babies and Nursing Infants, Department of Reconstructive Surgery of Newborns and Infants, Department of Emergen- 
cy Surgery of Newborns and Infants, Cardioplegia Laboratory, Express Diagnostics Laboratory, and Department of Morbid Anatomy with a prosectorium of Bakulev Scientific Center of Cardiovascular Surgery RAMS.

All subjects were divided into two groups according to cardioplegic solution used. Cardioplegia in the first group was performed using ACH solution (Bakulev Scientific Center of Cardiosurgery RAMS). In the second group Custodiol $^{\circledR}$ solution (Dr. Franz Köhler Chemie GmbH, Alsbach-Hähnlein, Germany) was used. The principal clinical diagnoses in both groups are represented in Table 1.

The first group comprised 20 patients: 11 male subjects and 9 female subjects. Mean age was $154.4 \pm 50.4$ days; mean age was $5.8 \pm 0.9 \mathrm{~kg}$.

The second group comprised 20 patients: 14 male subjects and 6 female subjects. Mean age was $138.1 \pm 39.5$ days; mean age was $5.7 \pm 0.6 \mathrm{~kg}$.

The study was conducted in compliance with the requirements of Ministry of Health of the Russian Federation and in agreement with Bakulev Scientific Center of Cardiovascular Surgery RAMS Ethical Committee. An informed consent was also obtained from the childrens' parents.

Patient's cardiovascular system condition on the preoperative state was evaluated by means of electrocardiography, echocardiography, and angiocardiography with cardiac catheterization. A continuous monitoring of heart rhythm and hemodynamics parameters was conducted during surgery. Moreover, arterial and venous blood samples for biochemical testing, needle and incisional biopsies for morphological examinationwere obtained at different stages of operation. A continuous monitoring of heart rhythm and hemodynamics parameters, echocardiographic and electrocardiographic monitoring was performed, and arterial and venous blood samples were obtained at the early postoperative period.

Anaesthetic support and perfusion were conducted according to methodology accepted in Bakulev Scientific Center of Cardiovascular Surgery RAMS. Induction agents were administered following insertion of a catheter in a peripheral vein: midazolam $(0.2-0.3 \mathrm{mg} / \mathrm{kg})$ and

Table 1. Principal clinical diagnoses in groups I and II.

\begin{tabular}{ccc}
\hline \multirow{2}{*}{ Principal clinical diagnosis } & \multicolumn{2}{c}{ Number of patients (\%) } \\
\cline { 2 - 3 } & Group I & Group II \\
\hline Transposition of the great arteries & $3(15 \%)$ & $3(15 \%)$ \\
Atrioventricularseptal defect & $3(15 \%)$ & $2(10 \%)$ \\
Tetralogy of Fallot & $7(35 \%)$ & $8(40 \%)$ \\
Rastelli type A Atrioventricular canal defect & $7(35 \%)$ & $7(35 \%)$ \\
Total & $20(100 \%)$ & $20(100 \%)$ \\
\hline
\end{tabular}

fentanyl (10 - $15 \mu \mathrm{g} / \mathrm{kg})$. Myoplegia was achieved with pipecuronium bromide (arduan) $(0.12 \mathrm{mg} / \mathrm{kg})$. After intubation patients were switched to artificial pulmonary ventilation in the normoventilation/moderate hypoventilation mode with $\mathrm{FiO}_{2}=40 \%$ in the setting of PEEP $2-4$ $\mathrm{cm} \mathrm{H}_{2} \mathrm{O}$. Maintenance of anesthesia was achieved with fentanyl (cumulative dose $50-120 \mu \mathrm{g} / \mathrm{kg}$ ) administered continuously during the operation, and intermittent administration of midazolam $(0.1 \mathrm{mg} / \mathrm{kg} / \mathrm{h})$ and arduan $(0.05$ $\mathrm{mg} / \mathrm{kg}$ before cardiopulmonary bypass). Heparin was administered in an amount of $3 \mathrm{mg} / \mathrm{kg}$. Protamine sulfate solution was used for heparin inactivation in the ratio of 1/06. -0.8 (protamine/heparine).

Cardiopulmonary bypass (CPB) was performed by means of bicavalcannulation using "venae cavae-aorta" method. CPB was conducted in the setting of hypothermia with rectal temperature of a patient $32^{\circ} \mathrm{C}-22^{\circ} \mathrm{C}$ on a "Stockert" pump (Germany) with "Lilliput-902" membrane oxygenator produced by "Dideco" company (Italy). The priming volume was about $450 \mathrm{ml}$ : heparin, erythromass-100 - $150 \mathrm{ml}, 15 \%$ mannitol $0.5 \mathrm{~g} / \mathrm{kg}$, correction solutions.

Cardioplegia was performed following achievement of moderate systemic hypothermia. To accomplish this, a purse-string suture was made on the anterior wall of ascending aorta, andaortotomywas made in its centre with consequent cannulation and fixation of the cannula with a tourniquet. Cardioplegic solution $\left(4^{\circ} \mathrm{C}-6^{\circ} \mathrm{C}\right)$ was administered into the aortic root under a pressure up to 60 $\mathrm{mm} \mathrm{Hg}$. The solution was administered by drop infusion by means of disposable infusion system.

Single dose cardioplegia with ACH BakulevScientific Center of Cardiovascular Surgery solution was performed in an amount of $1 \mathrm{ml} / 1 \mathrm{~g}$ of myocardium $/ \mathrm{min}$ or 40 $\mathrm{ml} / \mathrm{kg}$ over a time period of 6 - 8 minutes. Mean volume of solution used per patient was $350 \pm 84 \mathrm{ml}$. Composition of the solution is presented in Table 2 .

Table 2. Composition of Bakulev Scientific Center of Cardiosurgery RAMS ACH cardioplegic solution*.

\begin{tabular}{cc}
\hline Ingredient & Amount (mmol) \\
\hline Sodium chloride & 60 \\
Potassium chloride & 15 \\
Calciumgluconate & 0.03 \\
Magnesium chloride & 16 \\
Mannitol & 25 \\
Glucose & 5 \\
L-histidine & 5 \\
L-carnosine & 100 \\
N-acetylcarnosine & 40
\end{tabular}

* solution osmolarity is $330 \mathrm{mOsmol} / 1, \mathrm{pH} 7.3$ - 7.4. 
Single dose cardioplegia with intracellular Custodiol solution was performed in an amount of $1 \mathrm{ml} / 1 \mathrm{~g}$ of myocardium $/ \mathrm{min}$ or $40 \mathrm{ml} / \mathrm{kg}$ over a time period of $6-8 \mathrm{~min}$ utes. Mean volume of solution used per patient was 350 $\pm 84 \mathrm{ml}$. Composition of the solution is presented in Table 3.

External heart cooling with frozen saline solution was applied in both groups. Left ventricular venting catheter was inserted in the area of right superior pulmonary vein to prevent myocardial rewarming during aortic crossclamping and volume overload in the period of cardiac recovery.

After release of aortic clamp parallel perfusion was continued with gradual decrease in perfusion flow rate and patient rewarming till rectal temperature of $35^{\circ} \mathrm{C}$ $36^{\circ} \mathrm{C}$ is achieved.

All patients underwent definitive repair of congenital heart disease (CHD). The mean time of CPB in group I was $134.3 \pm 17.1$ minutes, aortic cross-clamping time was $61.8 \pm 5$ minutes. In group II the mean time of CPB was $117.7 \pm 15.5$, and aortic cross-clamping time was $64.3 \pm 7.7$ minutes $(\mathrm{p}>0.165)$.

Myocardial protection efficiency was evaluated during the operation and in early postoperative period by clinical course, biochemical testing and morphological examination data.

To perform clinical course analysis the following data were recorded: central hemodynamics parameters, need for prolonging $\mathrm{CBP}$, cardiac recovery pattern and duration of artificial pacemaker work. For evaluation of inotropic support degree catecholamine index was used [1]. Analysis of specific complications and morbidity was also performed.

Myocardial metabolism and systemic condition was monitored during the whole operation and early postope-

Table 3. Composition of intracellular custodiolcardioplegic solution".

\begin{tabular}{cc}
\hline Ingredient & Amount (mmol) \\
\hline $\mathrm{NaCl}$ & 15.0 \\
$\mathrm{KCl}$ & 9.0 \\
Potassiumhydrogen 2-ketoglutarate & 1.0 \\
$\mathrm{MgCl}_{2} \cdot 6 \mathrm{H}_{2} \mathrm{O}$ & 4.0 \\
Histidine- $\mathrm{HCl} \mathrm{H}_{2} \mathrm{O}$ & 18.0 \\
Histidine & 180.0 \\
Tryptophan & 2.0 \\
Mannitol & 30.0 \\
$\mathrm{CaCl}_{2}$ & 0.015 \\
\hline
\end{tabular}

* solution osmolarity is $310 \mathrm{mOsmol} / \mathrm{l}, \mathrm{pH} 7.02-7.20$. rative period by data on biochemical testing of blood obtained from radial artery and peripheral vein $\left(\mathrm{pH}, \mathrm{Sat} \mathrm{O}_{2}\right.$, $\mathrm{BE}$, lactate level) and by an increase in the blood level of myocardial necrosis markers.

Myocardial damage was monitored by the baseline venous blood level of creatine phosphokinase MB fraction and troponin- $\mathrm{T}$, measured before skin incision, and every 4 hours after patient's admission to the ICU. These biochemical parameters were chosen as increase in their blood level is a highly sensitive and specific marker of cardiomyocytes damage $[2,3]$. These were measured in venous blood samples as the artery cannula was removed following patient's transfer from ICU to a specialized department, while the testing was continued till the fifth postoperative day.

Morphological examination of the myocardium was performed at ultrastructural and light-optical level. Baseline patients' myocardial morphology and its alterations developing during the operation were examined using electron microscopy of needle biopsy samples obtained from right ventricular outflow tract before aortic clamping and after 30 minutes of reperfusion. Samples were obtained from 7 patients in group I and from 8 patients in group II. There were no significant differences in patients' mean age $(6.6 \pm 3.3$ months and $4.8 \pm 3.0$ months, respectively) and mean time of aortic cross-clamping (59 $\pm 11 \mathrm{~min}$. and $64 \pm 10 \mathrm{~min}$., respectively) between the 7 patients from group I and 8 patients from group II who underwent myocardial biopsy (Table 4). Biopsy samples were fixed in $2.5 \%$ glutaraldehyde solution and $1 \%$ paraformaldehyde solution and post-fixed in 1.5\% osmium tetroxyde solution. Then samples were dehydrated and embedded in araldite. Ultrathin sections were prepared on the ultramicrotome LKB, counterstained with uranyl acetate and lead citrate and examined with a Philips CM100 electron microscope (the Netherlands). To reveal ischemic damage in cardiomyocytes intraoperative chande in glycogen level and condition of mitochondria was evaluated. Glycogen level was determined by a 6-point scale: high (5), significant (4), moderate (3), low (2), glycogen present as solitary granules (1), glycogen absent (0). Mitochondria were evaluated by a 5-point scale using a visual index (mitochondrial index-Imch), which is descriptive of mitochondrial matrix condition and the cristal packing density: 5-condensed mitochondria with compact matrix, 4, 3, 2, and 1-orthodox mitochondria with areas of electron-transparent matrix and cristae packed compact (4), loose (3), with mild (2) or significant (1) separation. For a more detailed evaluation an additional fractionary " 4.5 " point was established descriptive of a transient mitochondrial condition-condensed mitochondria with reduced matrix electron density.

Incisional biopsy samples from right atrial myocardium obtained before aortic cross-clamping and before 
Table 4. Glycogen level and mitochondrial index in patients' cardiomyocytes at baseline and at the end of open-heart surgery.

\begin{tabular}{|c|c|c|c|c|c|c|}
\hline \multirow{2}{*}{$\begin{array}{l}\text { Subject No. and } \\
\text { biopsy No. }\end{array}$} & \multirow[b]{2}{*}{ Age (mon.) } & \multirow{2}{*}{$\begin{array}{l}\text { Aortic cross-clamp } \\
\text { time (min.) }\end{array}$} & \multicolumn{2}{|c|}{ Glycogen } & \multicolumn{2}{|c|}{ Imch } \\
\hline & & & $\begin{array}{l}\text { Median (range) } \\
\text { (standard units) }\end{array}$ & Mann-Whitney test (p) & $\begin{array}{l}\text { Median (range) } \\
\text { (standard units) }\end{array}$ & Mann-Whitney test (p) \\
\hline \multicolumn{7}{|c|}{7 subjects in group $\mathrm{I}(\mathrm{ACH})$} \\
\hline $\begin{array}{l}1(1) \\
1(2)\end{array}$ & 2.5 & 60 & $\begin{array}{c}3(2-4) \\
2.5(2-3)\end{array}$ & 0.189 & $\begin{array}{l}4(3-4.5) \\
4(3-4.5)\end{array}$ & 0.513 \\
\hline $\begin{array}{l}2(1) \\
2(2)\end{array}$ & 9 & 36 & $\begin{array}{l}3(2-3) \\
2(2-4)\end{array}$ & 0.867 & $\begin{array}{l}4.5(4-4.5) \\
4.5(4-4.5)\end{array}$ & $<0.0001$ \\
\hline $\begin{array}{l}3(1) \\
3(2)\end{array}$ & 3 & 65 & $\begin{array}{l}3(2-3) \\
3(2-4)\end{array}$ & 0.194 & $\begin{array}{l}4.5(4-4.5) \\
4.5(4-4.5)\end{array}$ & 0.816 \\
\hline $\begin{array}{l}4(1) \\
4(2)\end{array}$ & 6 & 59 & $\begin{array}{l}3(2-4) \\
3(2-4)\end{array}$ & 0.841 & $\begin{array}{c}4.5(4.5-5) \\
4.5(4-5)\end{array}$ & 0.414 \\
\hline $\begin{array}{l}5(1) \\
5(2)\end{array}$ & 12 & 67 & $\begin{array}{l}3(1-4) \\
2(1-3)\end{array}$ & 0.038 & $\begin{array}{l}4.5(3-4.5) \\
4.5(3-4.5)\end{array}$ & 0.165 \\
\hline $\begin{array}{l}6(1) \\
6(2)\end{array}$ & 6.5 & 60 & $\begin{array}{l}3(2-4) \\
3(2-4)\end{array}$ & 0.282 & $\begin{array}{l}4.5(4-4.5) \\
4.5(4-4.5)\end{array}$ & 0.724 \\
\hline $\begin{array}{l}7(1) \\
7(2)\end{array}$ & 7.5 & 68 & $\begin{array}{c}3(2-5) \\
3.5(2-5)\end{array}$ & 0.192 & $\begin{array}{l}4.5(4-4.5) \\
4.5(4-4.5)\end{array}$ & 0.974 \\
\hline Mean \pm std. dev. & $6.6 \pm 3.3$ & $59 \pm 11$ & & & & \\
\hline \multicolumn{7}{|c|}{8 subjects in group II (Custodiol) } \\
\hline $\begin{array}{l}1(1) \\
1(2)\end{array}$ & 3 & 62 & $\begin{array}{l}3(2-4) \\
3(2-5)\end{array}$ & 0.830 & $\begin{array}{c}4.5(4-5) \\
4.5(4-4.5)\end{array}$ & 0.366 \\
\hline $\begin{array}{l}2(1) \\
2(2)\end{array}$ & 1.8 & 57 & $\begin{array}{l}3(2-4) \\
2(1-4)\end{array}$ & 0.016 & $\begin{array}{l}4.5(4-5) \\
4.5(4-5)\end{array}$ & 0.625 \\
\hline $\begin{array}{l}3(1) \\
3(2)\end{array}$ & 3.3 & 66 & $\begin{array}{l}2(1-3) \\
2(1-4)\end{array}$ & 0.808 & $\begin{array}{l}4.5(3-4.5) \\
4.5(3-5)\end{array}$ & 0.323 \\
\hline $\begin{array}{l}4(1) \\
4(2)\end{array}$ & 4.8 & 70 & $\begin{array}{l}3(2-4) \\
3(2-4)\end{array}$ & 0.611 & $\begin{array}{l}4.5(4-5) \\
4.5(4-5)\end{array}$ & 0.717 \\
\hline $\begin{array}{l}5(1) \\
5(2)\end{array}$ & 11.8 & 62 & $\begin{array}{l}3(2-5) \\
3(2-3)\end{array}$ & 0.239 & $\begin{array}{l}4.5(4-5) \\
4.5(4-5)\end{array}$ & 0.014 \\
\hline $\begin{array}{l}6(1) \\
6(2)\end{array}$ & 4 & 83 & $\begin{array}{l}2(1-3) \\
3(2-3)\end{array}$ & 0.261 & $\begin{array}{l}4.5(4-4.5) \\
4.5(4-5)\end{array}$ & 0.290 \\
\hline $\begin{array}{l}7(1) \\
7(2)\end{array}$ & 5 & 50 & $\begin{array}{l}3(2-4) \\
3(2-4)\end{array}$ & 0.352 & $\begin{array}{c}4.5(4-5) \\
4.5(4-4.5)\end{array}$ & 0.415 \\
\hline $\begin{array}{l}8(1) \\
8(2)\end{array}$ & 4.5 & 62 & $\begin{array}{l}3(2-4) \\
3(2-4)\end{array}$ & 0.825 & $\begin{array}{c}4.5(3-5) \\
4.5(4-4.5)\end{array}$ & 0.859 \\
\hline Mean \pm std. dev. & $4.8 \pm 3.0$ & $64 \pm 10$ & & & & \\
\hline $\begin{array}{l}\text { T-test between } \\
\text { groups I and II }\end{array}$ & $P=0.279$ & $P=0.396$ & & & & \\
\hline
\end{tabular}

aortic declamping were examined at light-optical level using histochemistry method. The usage of right atrial myocardium instead of ventricular myocardium for evaluation of protection against cardioplegic ischemia was dictated by the necessity of reducing the injury. Myocardium blocks were frozen by petroleum ether cooled to $-79^{\circ} \mathrm{C}$ temperature. Sections $7-10 \mu \mathrm{m}$ thick were prepared in a Leica Microsystems CM1515 thermostatic cooler at $-20^{\circ} \mathrm{C}$ and were consequently stained with hematoxylin and eosin in "Leica/Jung Autostainer XL" modular apparatus (Germany), with Oil Red O to reveal triglycerides, and with Shiff-reaction staining to determine glycogen cardiomyocytes content. Succinate dehydrogenase (SDG) was also measured. The preparations were examined with "Leica DM LS" microscope (USA).

Statistical analysis was performed by means of parametric and nonparametric statistical methods. STATISTICA 10.0 software package was used. Arithmetical mean value $(\mathrm{M})$, standard deviation $(\sigma)$, root mean square error $(\mathrm{T})$, and confidence intervals were estimated for quantitative parameters. Statistical significance was evaluated by Student's t-test. Rank parameters were expressed as median value and range of values: the significance of these parameters was evaluated by means of nonpara- 
metric Mann-Whitney test for pair-wise group comparison. In our study we established the significance level of $\mathrm{p}<0.05$.

\section{RESULTS}

There was no significant difference between two study groups in mean values of age, weight, left ventricular ejection fraction (LV EF), systolic and diastolic arterial pressure, level of creatine phosphokinase MB fraction (CPK-MB) and troponin-T (TN-T) (Table 5).

During the operation electromechanical cardiac arrest in the ACH-solution group occurred at second 15.3 \pm 2.7 , while in HTK-solution group cardiac arrest occurred at second $27.4 \pm 4$ after the beginning of cardioplegia. This parameter was significantly different between study groups $(\mathrm{p}<0.0001)$.

We reported spontaneous cardiac recovery following aortic declamping in both groups. In the first group cardiac recovery occurred in $57 \pm 22$ seconds, and in the second group - in 54.1 \pm 11.7 seconds ( $\mathrm{p}>0.8)$.

Based on echocardiographic data, LV EF on the first day following surgery in groups I and II was $54.0 \pm 4.1 \%$ and $55.2 \pm 2.65$, respectfully $(\mathrm{p}>0.654)$, while on the second day following surgery $-58.1 \pm 2.6$ and $56.4 \pm 3.3$. The difference between groups was not significant $(\mathrm{p}>$ $0.41)$.

According to monitoring data the values of systolic and diastolic pressure were not significantly different between study groups throughout the observation $(p>0.05)$ (Figures 1(a) and (b)).

Catecholamine index following discontinuation of CPB in the first and second groups was $13.5 \pm 7.2 \mu \mathrm{g} / \mathrm{kg} / \mathrm{min}$ and $11 \pm 4.6 \mu \mathrm{g} / \mathrm{kg} / \mathrm{min}$, respectively $(\mathrm{p}>0.654)$. There was no difference between groups ( $p>0.05)$ (Figure 2).

According to biochemical data analysis, no significant differences were reported beyween groups in the level of CPK-MB and TN-T (p > 0.05) (Figures 3(A) and (B)).

Table 5. Mean values of age, weight, left ventricular ejection fraction (LV EF), systolic and diastolic arterial pressure, level of creatine phosphokinase MB fraction (CPKMB) and troponin-T (TN-T).

\begin{tabular}{cccc}
\hline & ACH & Custodiol & Student's test \\
\hline Age (days) & $154.4 \pm 50.4$ & $138.1 \pm 39.5$ & $\mathrm{p}>0.62$ \\
Weight (kg) & $5.8 \pm 0.9$ & $5.7 \pm 0.6$ & $\mathrm{p}>0.809$ \\
Baseline EF (\%) & $67.9 \pm 0.4$ & $67.6 \pm 1.2$ & $\mathrm{p}>0.631$ \\
Baseline SAP (mmHg) & $77.8 \pm 6.7$ & $84.9 \pm 4.7$ & $\mathrm{p}>0.098$ \\
Baseline DAP (mmHg) & $42.9 \pm 3.5$ & $49.5 \pm 2.8$ & $\mathrm{p}<0.006$ \\
Baseline CPK-MB (ng/ml) & $8.1 \pm 5.1$ & $4.9 \pm 1$ & $\mathrm{p}>0.337$ \\
Baseline Tn-T (ng/ml) & $0.32 \pm 0.54$ & $0.07 \pm 0.06$ & $\mathrm{p}>0.437$ \\
\hline
\end{tabular}

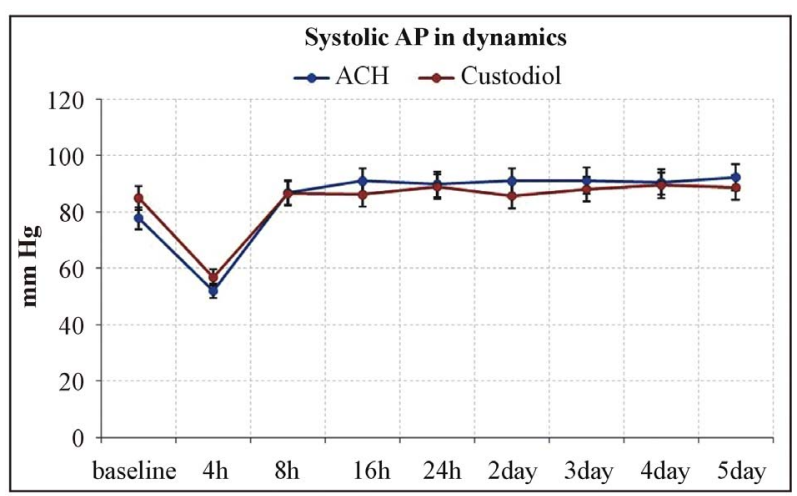

(A)

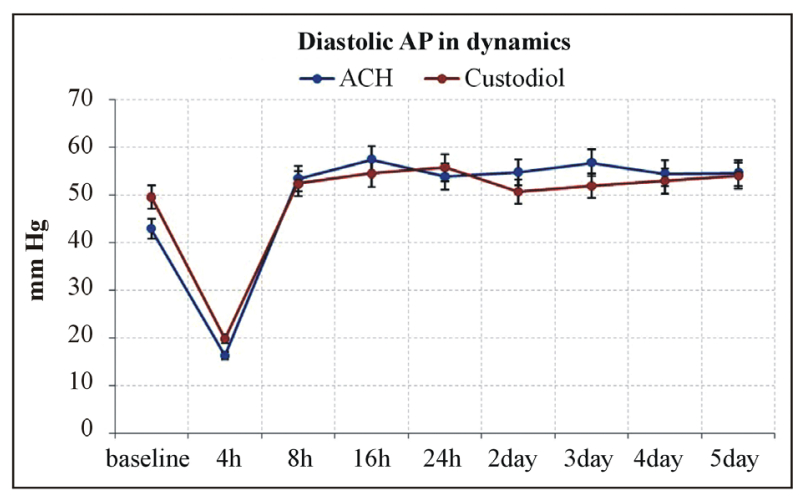

(B)

Figure 1. (A) Systolic AP in dynamics; (B) Diastolic AP in dynamics.

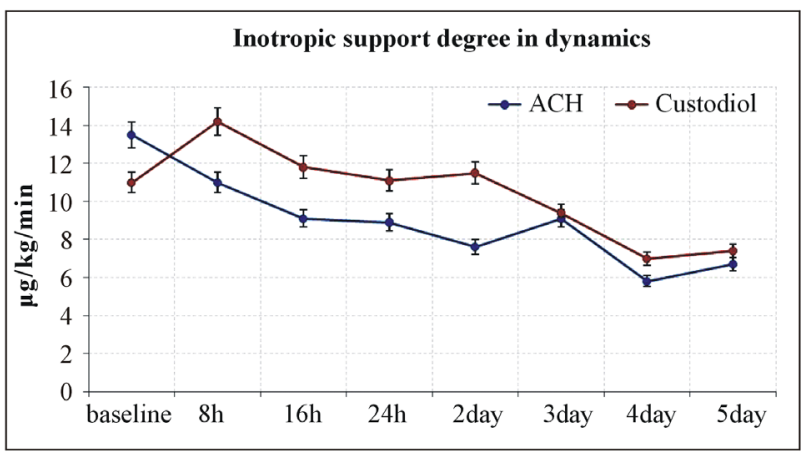

Figure 2. Inotropic support degree in dynamics.

Duration of artificial pulmonary ventilation and duration of stay in ICU in the first group were $110 \pm 32.68$ hours and $131.8 \pm 36.36$ hours, respectively, while in the second group $-91.28 \pm 40.9$ and $132.9 \pm 60.56$ hours, respectively. There also was not significant difference in these parameters between groups $(\mathrm{p}>0.488)$.

64 biopsies were investigated with light-optical microscope in children from both groups of which 18 samples were obtained from children with Atrioventricular canal defect diagnosis, 22-from Tetralogy of Fallot patients, 6-from atrioventricularseptal defect patients, 12 - from children with transposition of great arteries. 
Notably, myocardial lipidosis was not reported in any of the biopsies regardless of the cardioplegic solution used during surgery. Generally, glycogen content in the first biopsy samples obtained from patients in both groups was high, while in decreased in the second sample. However glycogen content was typically focal, that is myocardial areas with low glycogen content were found along with areas rich in glycogen. SDG activity was reported to be high in the first samples in both groups, and did not significantly reduce in the second samples obtained from all subjects (Figures 4(A) and (B)).

Electron microscopy of patients' RV outflow tract myocardium revealed cariomyocytes different in size and the degree of ultra structural maturity. Most of cardiomyocytes appeared to be small cells with severely curved

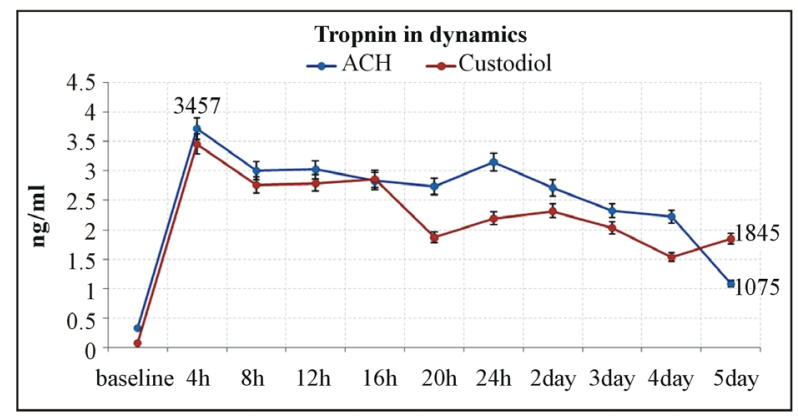

(A)

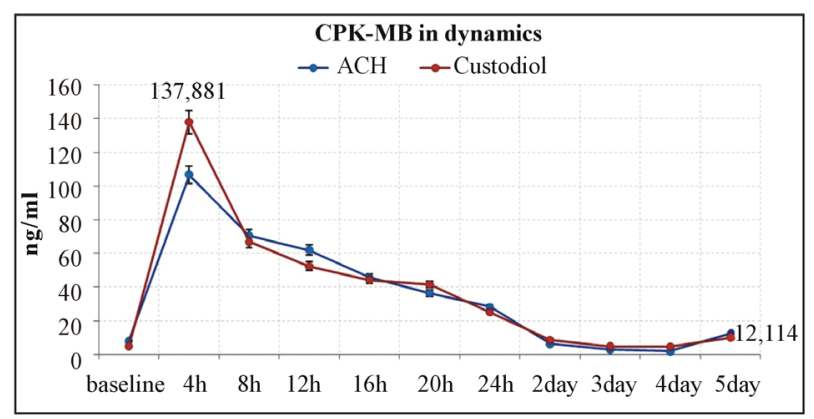

(B)

Figure 3. (A) Troponin-T in dynamics; (B) CPK-MB in dynamics.

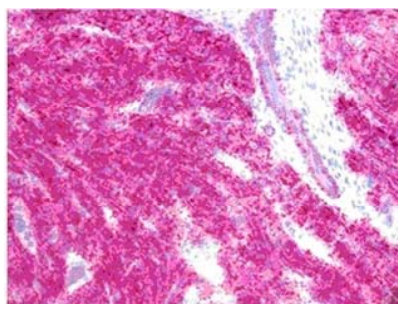

(A)

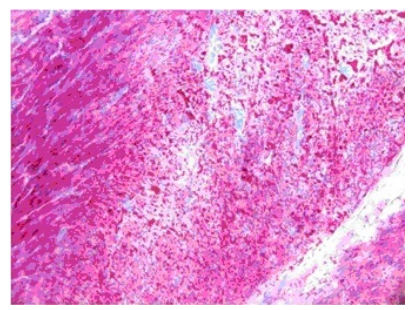

(B)
Figure 4. (A) High glycogen content in the first biopsy of patient K. Shiff-reaction staining. Magnification 10 oc. $\times 20$ obj; (B) Focal glycogen content decrease in the second biopsy of patient K. Shiff-reaction staining. Magnification 10 oc. $\times 20$ obj. nuclear membrane and a layer of sarcoplasm, in which a structured contractile apparatus is located with focuses of continuing myofibrils assembly. In some cells Golgi complex and, at a lesser extent, rough endoplasmic reticulum tubules were well developed. Specific atrial granules were often present in Golgi complex, while centrioles were extremely rare. We reported signs of dystrophy in many cells: deposition of lipofuscin granules, glycosomes different in size, lipid droplets, myelin-like bodies. Glycogen content was variable in cardiomyocytes. Generally, it was moderate, and less frequentlyit was low. Mitochondria varied in conformation: in most cases they were condensed with low matrix electron density (Imch $=4,5$ ); much less frequently mitochondria were in orthodox condition ( $\operatorname{Imch}=4$ or Imch $=3$ ) (Table 4).

Comparison of glycogen level and mitochondrial index in patients' cardiomyocytes before aortic cross-clamping and after 30 minutes of reperfusion allowed us to identify significant decrease in glycogen level during the operation from moderate to low in 1 patient out of 7 patients from group I (age-1 year, aortic cross-clamping time- 67 minutes) and in 1 patient out of 8 patients in group II (age- 1.8 months, aortic cross-clamping time57 minutes). We reported significant decrease in mitochondrial index during surgery in 1 patient's cardiomyocytes out of 7 patients from group I (age -9 months, aortic cross-clamping time-36 minutes) and in 1 patient's cardiomyocytes out of 8 patients in group II (age-11.8 months, aortic cross-clamping time-62 minutes). The reported alterations in glycogen level or mitochondrial condition were mild and found only in solitary patients in both groups, which confirms good protective properties of cardioplegic solutions used (Figure 5).

\section{DISCUSSION}

The results of our study demonstrate high efficiency of myocardial protection from one-hour intraoperative ischemia in children less than one year of age with congenital heart disease when using the new cardioplegic ACHsolution. The results are based on hemodynamics parameters analysis after recovery of cardiac function such as systolic and diastolic arterial pressure, catecholamine index, spontaneous cardiac recovery. Comparative analysis of clinical, biochemical, and morphological data did not reveal any significant difference in parameters studied between patients who received ACH cardioplegic solution and patients who received Custodiol.

The new cardioplegic three natural dipeptides-based solution showed high efficiency comparable to Custodiolcardioplegic solution, the latter having long ago gained a reputation of a highly effective medicinal product in many clinics worldwide that is used not only as a cardioplegic solution but also a solution for organ transplantation.

Hopefully, further clinical studies of this solution will 


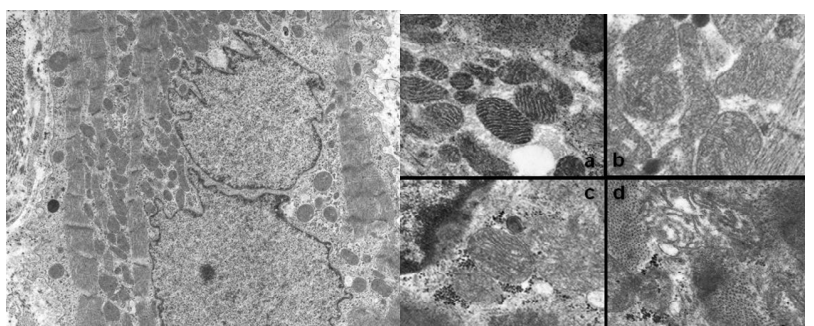

(A)

(B)

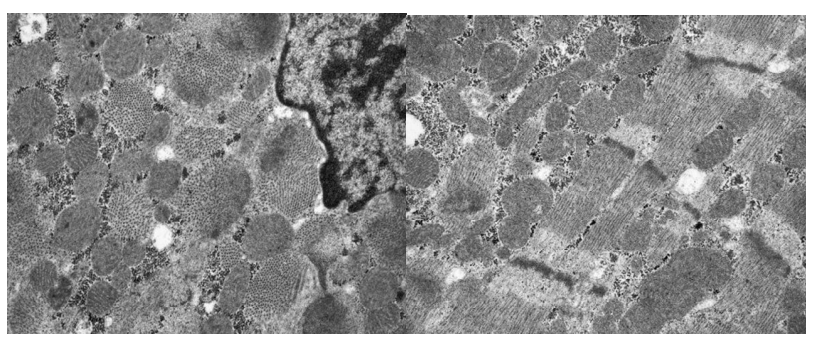

(C)

(D)

Figure 5. (A) Longitudinal section of a cardiomyocyte: nucleus with dispersed chromatin and severelycurved nuclear membrane, solitary structured myofibrils, mitochondrial clumps and chains, glycogen granules. Patient M., 9 months. Magnification $\times$ 4800. (B) Mitochondrial ultrastructure evaluation according to scale using mitochondrial index: $\mathrm{a}-\operatorname{Imch}=5 ; \sigma-\operatorname{Imch}=4,5 ; \mathrm{B}-\operatorname{Imch}=4 ; \Gamma-\operatorname{Imch}=3$. (C) Nuclear fragment, cross and diagonally cut myofibrils, condensed mitochondria with low matrix electron density $($ Imch $=4,5)$, solitary condensed mitochondria with high matrix electron density $($ Imch $=5)$, moderate glycogen content $(\mathbf{G l}=3)$, vacuoles. Condition before aortic cross-clamping. Magnification $\times 15,000$. (D) Cross and diagonally cut myofibrils, clumps of condensed mitochondria with low matrix electron density $(\operatorname{Imch}=4,5)$, moderate glycogen content $(\mathrm{GI}=3)$, vacuoles. Condition after 30 minutes of reperfusion, in 59 minutes after aortic cross-clamping. Patient K., 6.5 months. Magnification $\times \mathbf{1 5 , 0 0 0}$. reveal new opportunities with the solution developed in our center.

\section{REFERENCES}

[1] Cruz, D.N., Antonelli, M., Fumagalli, R., et al. (2009) Early use of polymyxin B hemoperfusion in abdominal septic shock. JAMA, 301, 2445-2452.

[2] Reithmann, C., Reber, D., Kozlik-Feldmann, R., et al. (1997) A post-receptor defect of adenylyl cyclase in severely failing myocardium from children with congenital heart disease. European Journal of Pharmacology, 330, 79-86.

[3] Ross, R.D. (2001) Grading the graders of congestive heart failure in children. Journal of Pediatrics, 138, 618-620. 